\title{
Procesos de articulaciones socio-identitarias y reformulaciones étnicas en Atacama ${ }^{1}$
}

\section{RESUMEN}

Este artículo se centra en el desarrollo de la etnicidad de los atacameños del norte de Chile, a través de sus múltiples interrelaciones con el Estado y la sociedad civil de Chile, en particular el mercado de trabajo minero y el arribo de la burocracia estatal a las comunidades indígenas. Esta fuerte conexión con la sociedad nacional, la entendemos como una vía estratégica y dramática de sobrevivencia étnica, en un entorno político difícil y agresivo.

\begin{abstract}
This paper centers on the development of Atacamenian ethnicity in northern Chile by means of their multiple relationships with the State and the civil society. It particularly focuses on the mining labour market and the arrival of the State's bureaucracy into the indigenous communities. The strong link with the Chilean national society is understood as a dramatic and strategic way of ethnic survival in a hard and aggressive political enviroment.
\end{abstract}

\section{Presentación}

La etnia atacameña es en Chile una de las más pequeñas en cuanto a su tamaño demográfico, estimándose en unos 12.000 el número de sus integran-

1 Este artículo se inscribe dentro del Proyecto Fondecyt $\mathrm{N}^{\circ}$ 1970644 (1997-1998): «De indio a ciudadano: Etnicidact, identidad étnica e incorporación indígena a la sociedad nacional en el norte de Chile, en comparación con los Andes de Perú, Bolivia y Ecuador (1824-1995)»

2 Antropólogo, Instituto de Investigaciones Arqueológicas y Museo Universidad Católica del Norte. San Pecho de Atacama. tes (aunque para algunos sólo llegan a 4.000). Se encuentran distribuidos en una área relativamente amplia de la IIa Región de Antofagasta en el norte de Chile, región que se encuentra enclavada en uno de los desiertos más áridos del planeta, la que a su vez posee también una importante riqueza minera. Este es sin duda, uno de los soportes estratégicos axiales de la economía de Chile en su conjunto.

\section{Consideraciones étnicas sobre Atacama}

La etnia atacameña no obstante lo pequeño de su tamaño demográfico, presenta complejidades y diferenciaciones socioculturales de una amplia cobertura. Geográfica, cultural e históricamente se reconocen dos grandes áreas:

La cuenca del río Loa - río Salado: en donde habitan los denominados atacameños del norte. Estos se encuentran en la única hoya hidrográfica que desemboca en el océano Pacífico, es decir, es un corredor transversal que une con mayor facilidad los diversos pisos ecológicos de la región (costa, desierto, piedemonte y alta puna), desde épocas que se pierden en el tiempo. Este corredor ha sido utilizado para el tránsito de volúmenes significativos de población. Lipez, Quechuas y Aymaras fundamentalmente, han circulado y se han asentado en esta zona, coexistiendo y mezclándose con los Atacameños, en una serie de hibridaciones culturales, producto de relaciones interétnicas pobremente estudiadas hasta el momento. Hoy, no obstante que sus habitantes se autorreconocen como atacameños, las influencias de otras etnias andinas es palpable con bastante notoriedad.

Cuenca del Salar de Atacama: Aquí se encuentran los atacameños del sur, quienes ocupan la hoya hidrográfica endorreica del Salar de Atacama, donde está San Pedro de Atacama. una zona relativamente más aislada, aunque históricamente han existido amplios y numerosos contactos con otras etnias, estos no han tenido la masividad del Loa. En esta zona, se produjeron los niveles más altos ele complejidad 
social y cultural en el llamado desarrollo cultural prehispánico atacameño, aproximadamente por el primer milenio de nuestra era. Más tarde, el Corregimiento (modalidad de gobierno de la Corona española) tuvo aquí su sede, en Atacama la Grande, hoy San Pedro de Atacama. En principio, la administración eclesiástica de la región (en su momento parte indisoluble del poder político), estuvo en la Doctrina de Chiu-Chiu o Atacama La Chica, en la zona transicional del Loa, aledaña a la ciudad de Calama (a unos 31 kilómetros de ésta). Esta zona eje de nuestros análisis y reflexiones, ha tenido a lo largo de su historia de post conquista europea, una larga serie de influencias de la sociedad mayor, sobre todo de índole político-administrativa, más que económica.

No obstante sus diferencias, los habitantes de ambas zonas se reconocen a sí mismos como atacameños, incluidos los de la zona del Loa, quienes poseen un acervo cultural que es producto de una mayor convergencia de migraciones, quechuas y aymaras, que aquéllos de la zona del Salar de Atacama. En contra de las visiones más pesimistas, esta unidad de auto rreconocimiento se ha mantenido a pesar de las innumerables circunstancias que han atentado contra la supervivencia de este grupo étnico. Particularmente, postulamos que la masiva y hegemónica ingerencia de la sociedad mayor, hispana y republicana (boliviana y chilena), han golpeado y aculturado a los atacameños, no podemos negarlo, pero al analizar de un modo específico, punto por punto, los diversos elementos constitutivos e interrelaciones estructurales, que hoy por hoy, caracterizan a la etnia atacamefia, nos encontramos que en conjunto con estas arremetidas aculturadoras, ha existido una capacidad de reacción y de sincretismo cultural, unido a la rearticulación de espacios organizacionales, dentro de los cuales no sólo se han configurado reductos de refugio y sobrevivencia étnico-cultural, sino que también estos refugios han servido de un modo muy cauteloso como una suerte de plataformas de «inserción activa» en los espacios de la modernidad. En el caso atacameño, consideramos que uno de estos espacios de primerísima importancia, el cual no ha sido realmente estudiado, excepto menciones tangenciales, es y ha sido el mercado de trabajo asalariado, lo que no ha negado el lugar también importante de la economía informal, pero ésta no ha sido tan protagónica como entre los aymaras de Tarapacá (Chile), o en Bolivia o Perú. El mercado de trabajo asalariado en Atacama presenta algunas condiciones especiales que lo distinguen de otras regiones andinas en general, y de la región cultural aymara de Tarapacá, la otra etnia centro-sur andina de Chile. En particular, el eje de esta distinción radica en la permanencia a través del tiempo de la actividad minero-extractiva de gran envergadura, en lo que se denomina «la gran minería industrial».

\section{Un caso clave: San Pedro de Atacama}

A comienzos del siglo XVII, se estableció el Corregimiento de Atacama, en San Pedro de Atacama. En él destacó la figura del Corregidor don Juan Velásquez de Altamirano (en 1663), quien como parte de una gestión de usufructo personal y de contribución a la arcas de la Corona, instaura oficialmente el tráfico de pescado seco desde la caleta de Cobija en el océano Pacífico, hasta el mineral de Potosí, en el Alto Perú, utilizando la precolombina práctica del tránsito de caravanas (Hidalgo, 1983; Núñez y Dillehay, 1995 [1978]). Con el tiempo, el volumen y la variedad de las mercancías aumentaron notablemente, ya no sólo desde Cobija, sino también desde los oasis atacameños, en especial las exacciones de San Pedro de Atacama. El Corregidor implantó también una severa política de cobros de impuestos a los indígenas, a raíz de la cual muchos de los mismos se vieron obligados a huir de sus tierras a los valles transcordilleranos, al no poder cubrir con las obligaciones fiscales (Hidalgo, 1987). Debiendo ser seguidos por los Kurakas o Caciques de los Ayllos, durante extensas jornadas a enormes distancias, para cobrarles el tributo, ya que de lo contrario serían ellos, los propios Kurakas, quienes deberían pagar las deudas de sus indígenas.

Esta situación trajo consigo grandes consecuencias. Primero, el abandono de tierras de cultivo y barbecho, con lo que aumentó el monto de tierras disponibles para la producción de mercancías destinadas al intercambio y la venta, especialmente con los centros mineros altiplánicos, como Potosí. Convirtiéndose San Pedro de Atacama en un centro proveedor de insumos, tales como sebo animal, forraje, cordelerías, etcétera. Segundo, esto llevó a reorientar la economía local, del autoconsumo a la exportación, lo cual fue casi totalmente controlado por las autoridades de la Corona, o por los caciques locales, por lo que si bien hubo aumento del intercambio, la mercantilización sólo se limitó a un selecto grupo de la sociedad local. Tercero, el Kuraka, al tener que apoyar a la administración colonial, se fue desligando paulatinamente de la base social de su poder indígena, transformándose en un intermediario entre 
los funcionarios de la Corona y la población local. Situación que se agravó más desde 1781 en adelante, a raíz de la derrota de las sublevaciones indígenas lideradas por Tupác Amaru en toda la zona centrosur andina, y que tuvo en Tomás Paniri, habitante de la localidad de Ayquina, a su caudillo en la región atacameña. Como consecuencia de esto, las comunidades atacameñas y andinas en general, fueron severamente reestructuradas, agudizando este proceso ya implantado desde la conquista, minimizando aún más el poder de los jefes locales, quedando sólo con poder asignado (un poder nominal), con el fin de impedir a toda costa, cualquier atisbo de reconstitución de las jefaturas regionales, dado que estas centralizan el poder, ya que si reaparecían estas jefaturas lo más probable es que surgiría una nueva rebelión de carácter macrorregional.

A esto se unieron las reformas borbónicas en la administración del Estado y en la instrucción pública, que impusieron el modelo del Despotismo Ilustrado en la región, en especial gracias a la labor del Corregidor don Francisco de Argumániz (Hidalgo, 1984).

Las comunidades locales se encontraban atomizadas a la llegada de la naciente República de Bolivia (1825), lo cual no cambió mucho la situación. Los decretos sobre la tenencia de la tierra, dictadas por el Presidente Melgarejo, cambiaron el régimen de propiedad comunal a propiedad privada de la tierra. Ello significó un duro golpe a la base de sustentación de las autoridades comunitarias (Cajías, 1975). Tras la Guerra del Pacífico (1879-1884), y la incorporación a la República de Chile, resurge a fines del siglo XIX, un enorme auge minero (pero ahora en el propio Desierto de Atacama), con la masiva explotación de los yacimientos de salitre. Ello trajo consigo una voluminosa inmigración de población criolla del centro y sur de Chile, así como de extranjeros, surgiendo innumerables centros mineros, e incipientes ciudades, especialmente en la costa (Zapata, 1992). Se reactivó en gran escala la economía productora de insumos atacameños para el consumo de los centros mineros, apareciendo una nueva actividad, el arrieraje de ganado argentino, desde los valles jujeños, los que luego de una extenuante travesía por la cordillera de los Andes, hombres y animales, descansaban y se fortalecían, en los oasis piemontanos, especialmente San Pedro de Atacama, para reemprender el viaje a través del desierto. Este comercio fue controlado por una élite local, constituida normalmente por personas ajenas a la comunidad local, las que conformaron una suerte de pequeña burguesía, dado que el trabajo de los arrieros y la producción de forraje seguían la economía del trueque, pero la venta de la carne en los centros consumidores se pagaba en dinero metálico, lo que hacía muy rentable ese rol de intermediarios. Con todo, ésta fue la última época de auge económico del oasis de San Pedro de Atacama, antes de la dinámica presente.

\section{Segundo caso clave: Calama-Chuquicamata}

La economía contemporánea de Chile gira en torno a la minería industrial del cobre. La identidad regional criolla que llena, por su aparente inconsistencia, de problemas a los planificadores y autoridades gubernamentales, es en nuestra opinión una consecuencia de la difundida percepción de la migración transitoria, pero de un flujo constante, de los mineros criollos en la zona. Esta transitoriedad existe -no podemos negarlo- pero no es absoluta. Junto al yacimiento de cobre más grande y emblemático de Chile (Chuquicamata), existe una ciudad aledaña: Calama, la única ciudad de más de 100,000 habitantes inserta en pleno mundo andino en el norte de Chile. Esta ciudad es la muestra más palpable de la continuidad de la economía minero-extractiva. Primero la plata del mineral de Caracoles, luego el salitre hasta los años treinta y de allí en adelante el cobre, han hecho de esta ciudad el centro económico y administrativo de la aproximación de los atacameños a la modernidad. No es casualidad que aquí se encuentre el mayor número de atacameños, más que en las comunidades originarias. Cabe señalar que casi un $65 \%$ de la población atacameña es urbana. Calama, hoy es capital de la provincia El Loa, sede operacional de la CONADI (Corporación Nacional Indígena) de la IIa Región. Su importancia como polo de atracción indígena ha crecido, al punto que ya no sólo hay atacameños, sino también quechuas y aymaras de la la Región de'l'arapacá, así como también otros migrantes provenientes de Bolivia.

En síntesis, no se puede explicar la dinámica sociocultural de los atacameños sin tomar en cuenta los alcances económico-geográficos de esta ciudad minero-agrícola, la cual es una «punta de lanza» de la penetración de las políticas del Estado, eje del mercado de trabajo asalariado en la zona y ejemplo de la modernización, pero no del modernismo, dado que el tipo rudo del minero medio no es precisamente el modelo sublime de la modernidad que se pretende difundir desde la costa; más específicamente desde Antofagasta, capital de la II Región.

No obstante la diversificación de la economía 
chilena en las últimas décadas, ésta sigue girando en torno a la minería del cobre, dentro de la cual Chuquicamata es el yacimiento emblemático. No sólo Calama no sería como es ahora sin Chuquicaunata, sino que toda la región y el norte de Chile, en general, se sustentan directa o indirectamente en la gran minería industrial. Como es comprensible, su influencia sobre las comunidades atacameñas ha sido gravitante.

\section{El contexto histórico-regional de la minería contemporánea en Atacama}

El cúmulo de evidencias etnohistóricas y etnográficas apuntan invariablemente a resaltar la enorme importancia que ha tenido el desarrollo de la minería en el devenir de la etnia atacameña. En tal sentido, su presencia trasciende la inmediatez de las últimas décadas de este siglo. Realizando una delimitación un tanto arbitraria, abordaremos por separado la minería artesanal o pequeña minería, de la minería industrial o gran minería. La minería artesanal no ha caracterizado a esta actividad económica en la IIa Región de Chile, debido fundamentalmente a restricciones medioambientales propias de la aridez del desierto. Por lo tanto, sólo aquellas vetas en extremo fecundas, fueron explotadas rudimentariamente en tiempos coloniales y precolombinos; tal fue el caso del yacimiento de Chuquicamata. La limitante fundamental es, como es lógico suponer, la falta de agua, en parte para solventar el traslado del material extraído por animales de carga, pero fundamentalmente el impedimento se centra en la imposibilidad de realizar los procesos de lixiviación u otro tipo de refinación del mineral en las contigüidades de los yacimientos.

Por lo tanto, la única posibilidad es llevar el agua por medio de costosas obras de ingeniería hidraúlica, desde sus escasas fuentes naturales, hasta los centros mineros y urbanos, tanto para procesar el material, como para el abastecimiento de la población humana ligada a esta actividad económica. Sólo los cuantiosos capitales privados y estatales, con una gran capacidad de decisión político-administrativa, han podido abordar este desafío. Ese fue el caso de las Oficinas Salitreras y el mineral argentífero de Caracoles, desde mediados del siglo XIX, y como ocurre actualmente con los enormes y medianos yacimientos cupríferos. Todo esto incide decisivamente en la formación de una masiva población de proletarios mineros, y no de mini empresarios independientes, no obstante la existencia de estos últimos. Por lo de- más, no es sólo el contexto geográfico-ecológico el que incide en ello, sino que desde el punto de vista histórico, estos territorios fueron el motivo por el cual se inició la Guerra de Pacífico, siendo la riqueza minera la principal variable en juego. Alrededor de ésta, las grandes inversiones prestamente desplazaron a aquéllas de menor tamaño (Blakemore, 1978), por lo que nos encontramos frente a un desarrollo histórico crecientemente macro capitalista.

En una sobre simplificada visualización, podemos apreciar, entonces, la existencia de una economía mayor tanto nacional como internacional, la cual tiene «enclaves» en esta región del Desierto de Atacama. En tales condiciones de explotación el mercado minero ya debe estar lo suficientemente consolidado, como para justificar grandes inversiones que permitan solucionar prácticamente todos y cada uno de los problemas logísticos de aprovisionamiento, junto con aquellos que se relacionan con condiciones globales de comercialización internacional. La magnitud de las inversiones y los desafíos medioainbien-tales, requieren en una mayor medida un manejo tecnológico avanzado para rentabilizar la explotación de la minería metálica; por lo menos más que en otras regiones de los Andes, también con gran minería metálica, pero con más humedad medioambiental, como en el caso de Cerro de Pasco, en la sierra peruana (De Wind, 1985).

Sin negar lo anterior, el mineral de Chuquicamata, centro de nuestra atención, presenta una evolución histórica particular. En el momento de su fundación en 1912, la minería del cobre tenía una importancia secundaria (lo que se revertiría a los pocos años). La compañía Guggenheim, unificó las muchas pequeñas posesiones mineras contiguas, hasta formar el gran yacimiento que hoy es, y a su vez comenzó a dar curso a masivas inversiones logísticas y de infraestructura, para hacer rentable la extracción de cobre; sin embargo, mostrando falta de sagacidad y visión de futuro, Guggenheim vende el yacimiento completo en 1923 a la compañía Anaconda (Zapata, 1986: 193). Con el paso de las décadas, esto se develaría como un craso error, pues este yacimiento se constituyó a la larga en el soporte de la rentabilidad de la Anaconda Corporation a nivel mundial. En fin, lo que queda claro es que en su momento la minería del cobre, en general, y Chuquicamata, en particular, eran el pariente pobre de la minería del salitre. Pero, la tecnología de fijación del nitrógeno atmosférico se hizo cada vez más depurada, con lo que los nitratos sintéticos absorbieron a la larga la mayor parte del mercado consumidor de salitre en el mundo. 
A su vez, al aumentar la capacidad de generación de electricidad, y otros usos afines, el valor bursátil del cobre fue en constante aumento. Hay que señalar que este proceso fue paulatino, y en su periodo de crecimiento inicial las rentas y el nivel de vida en general de los obreros del salitre superaban a la de los obreros del cobre. Eso sí que las condiciones de vida de las salitreras no eran precisamente de bienestar; por el contrario, las comisiones parlamentarias de la época han dejado patéticos testimonios sobre las pésimas condiciones de vida de los mineros. De allí las grandes huelgas de 1890, 1907 y 1925 . Por todo lo cual, la oferta de mano de obra, en general escasa, era aún más limitada durante este primer momento en Chuquicamata. Desde el principio los trabajadores andinos, atacameños e inmigrantes bolivianos, tuvieron una acogida calurosa por parte de los directivos estadounidenses, más que el brindado por los directivos de las salitreras, donde se les asignaba a las labores de abastecimiento o a las labores más toscas y peligrosas.

La ascendente minería cuprífera resistió la crisis global deflacionaria de 1929. Para la minería del salitre, esta crisis fue una debacle de la que nunca ha podido recuperarse, significándole una caída a pique del mercado comprador, por lo que las medidas de austeridad violentamente se hicieron insuficientes, frente a la imparable baja de los precios de venta. Rápidamente los costes de producción primero emparejaron el nivel de las ganancias (en un lapso de breves semanas), y luego se comenzó a trabajar a pérdida. Esta situación, se tradujo en la quiebra de la inmensa mayoría de los centros salitreros, e incluso aquellos que no se declararon en bancarrota, redujeron al mínimo el personal, como una política de ajuste brutal que fue común en América Latina y el Mundo. El Estado chileno también intervino, aplicando las recientes «leyes sociales» de 1925, absorviendo fuerza laboral en obras públicas, y comprando salitre.

Como es de esperarse, la cesantía en la década de los treinta en todo Chile, pero especialmente en el norte salitrero, fue abrumadora. La minería se había constituido en un evidente «enclave», del comercio transnacional, mas no verdaderos «polos de desarrollo»; es decir, no se la había acompañado de una política de industrialización y/o de diversificación laboral primaria, secundaria y terciaria. Esto dado que el Estado siguió desde la conclusión de la Guerra del Pacífico una tendencia marcadamente rentista, en la extracción y venta de los minerales.

A pesar de esta crisis, un importante contingente de obreros del salitre pudo reubicarse en la minería del cobre. Estos trabajadores, si bien estaban cohesionados por las largas luchas sindicales, y una ideología revolucionaria combativa; sin embargo, una de las consecuencias de este cambio fue la disgresión ideológica y la multiplicación de estrategias sindicales, no haciéndolo apto ya para análisis políticos simplistas y/o preestablecidos, de allí las perplejidades ideológicas que han causado a los directivos chilenos después de la nacionalización de cobre, tanto en la Unidad Popular como en el gobierno militar (Zapata, 1986). Es decir, el arribo de este contingente proletario salitrero al cobre, no significó en lo absoluto una reproducción de las articulaciones políticas ni del ambiente ideológico imperante en la industria del salitre, si bien no hubo un giro total, las alternativas políticas se cornplejizaron visiblemente.

\section{San Pedro de Atacama y la Gran Minería industrial}

A partir de historias orales recopiladas en San Pedro de Atacama, se advierte su rol como abastecedor de insumos a las ciudades y centros salitreros significando una elitista bonanza económica. Con la invención del salitre sintético y fundamentalmente la Gran Crisis de 1929, se produjo el abrupto y masivo cierre de oficinas salitreras, con lo que la demanda de insumos y ganado también disminuyó dramáticanente. El golpe de gracia ocurrió finalmente en 1948, con la apertura del ferrocarril Salta (Argentina)- Antofagasta (Chile) por Socompa, con lo cual se hacía mucho más rentable subir el ganado al tren en Salta, y bajarlo en Antofagasta (la capital provincial), dejando obsoleto el circuito de arrieraje por las tierras atacameñas, configurándose así el colapso progresivo de la economía local abierta al mercado externo (Rivera, 1993).

Desde el punto de vista de la política local, junto con la crisis económica, hubo un cambio en el rol del Estado. Con la dictación de la Constitución de 1925 aparecen las leyes sociales, además de una orientación corporativista, con la fundación de la Corporación de Fomento de la Producción (CORFO) en 1939. Esto hizo posible que cada vez más intervinieran funcionarios del Estado en los asuntos locales, rivalizando con la gestión de las estructuras de poder locales (Rivera, 1994). De todos modos asignamos un rol protagónico, en esta crisis de sustentación y legitimidad del poder de la élite local a la paulatina fortaleza del centro minero de cobre de Chuquicanata y su ciudad asociada Calama. Creada en 1912 con 
capitales norteamericanos, la compañía Chile Exploration Company, constituyó la mina a cielo abierto más grande del mundo, y significó una continuidad minera en la región al sustituir el cobre al salitre.

Para los cuantiosos capitales transnacionales norteamericanos tenía escasa o ninguna importancia relacionarse con la élite local de poder. Es más, sus redes logísticas de abastecimiento hacían innecesarios los insumos locales. Lo que sí necesitaban era una mano de obra barata y eficiente, por lo que se acercaron a los atacameños sin tierra, a los más postergados y pobres, con el fin de convertirlos en obreros, en asalariados, quienes por provenir de una economía de trueque, al hacerles la convertibilidad monetaria, resultaban muy rentables. Además por su milenaria adaptación fisiológica al riguroso clima, soportaban en muy buena forma la rudeza de las condiciones del trabajo. Como consecuencia de esto, los sectores más paupérrimos y despreciados de la comunidad local, tuvieron un acceso directo a la modernidad como asalariados, recibiendo dinero metálico, acceso a servicios de salud, educación, etcétera. Recibieron la influencia de las culturas políticas y organizacionales modernas en los sindicatos y campamentos de Chuquicamata y los barrios populares de Calama. Es evidente que la élite local no pudo hacer frente a esta revolución, y al no tener ya un mayor rol intermediario que cumplir, colapsaron, frente a la penetración del Estado y del gran capital minero, terminando por emigrar mayoritariamente a la vida urbana (Rivera, 1994).

Las relaciones de poder en el interior de la comunidad de San Pedro de Atacama es donde probablemente mejor se refleja lo profundo que ha calado la interacción con la sociedad mayor. La expansión de esta comunidad desde hace mucho que se enfrenta a severas limitaciones, primero el evidente freno ecológico que significa el severo ambiente desértico de la región, luego la pobreza generalizada que impide una mayor capacidad de inversión y consumo, todo esto la hace tremendamente dependiente de los ingresos producidos en el exterior, los cuales llegan en una mínima cantidad a la comunidad, pero cumpliendo un rol fundamental, vía pensiones asistenciales contra la pobreza, jubilaciones, ayudas familiares de hijos u otros parientes que trabajan en la ciudad o en la minería.

\section{Intermediaciones y sujetos políticos en la interrelación sociocultural en Atacama}

En una primera impresión, la realidad cultural y política de la etnia atacameña genera múltiples perplejidades, al constatarse una gran cantidad de contradicciones en su devenir político, incluso se perciben diferencias que en un primer momento bien pueden atribuirse a tradiciones político-organizativas separadas o en proceso de crecientes divergencias estructurales. Frente a esta situación, consideramos que si bien existen diferencias organizacionales, los puntos de encuentro de las diversas alternativas de la gestión política de las comunidades Likán Antai (Atacameñas), son más avatares coyunturales en la correlación de fuerzas y la articulación de las mismas, que la gestación de nuevos proyectos políticos concretos, en proceso de separación, de una suerte de matriz cultural común. Postulamos que más que diferencias culturales, se trata de una alternancia de modos de organizarse, debido a la precariedad de los equilibrios de tenencia de tierras, capacidad de inversión, socialización de la cultura política (enculturación política), entre muchas otras variables. Todo lo cual redunda en la presencia episódica de estructuras con poder delegado y/o poder asignado. En esta falta de concreción institucional, ubicamos a actores socio-políticos de singular importancia: los intermediarios. En el vínculo entre las comunidades y su entorno mayor, llámese éste otras comunidades atacameñas, o los centros urbanos, el mercado de trabajo asalariado o, por supuesto, la institucionalidad del Estado chileno. El origen de estos intermediarios ha sido y sigue siendo múltiple, desde el interior de la comunidad, hasta lo más lejano de su externalidad, el contexto nacional o incluso orígenes internacionales.

Entendemos por intermediarios a aquellas personas que han ocupado posiciones relevantes en la interrelación entre la etnia atacameña y la sociedad nacional chilena, en donde la fuente de su prestigio, autoridad o cualquier otra forma de poder gira en torno a esta imbricación estructural comunidad-sociedad mayor. El caso histórico paradigmático durante el período colonial fue el de los Kurakas, o jefes locales de los Ayllos, o comunidades de parentesco y propiedad de la tierra. Hidalgo (1987a y 1987b), muestra su paulatina desvinculación de la base comunitaria de la delegación de su poder, lo que trajo consigo el desprestigio de la asignación de su linaje como «Principal» de la localidad, para convertirse con el paso del tiempo en un instrumento más de la 
dominación hispana, especialmente en lo referente a las exacciones fiscales que imponía la administración de la Corona en la región atacameña, llegando incluso a complementar la recaudación de impuestos, so castigo de tener que solventarlos él mismo, si es que los miembros de la comunidad evitaban pagarlos.

Durante el siglo XX, en los primeros treinta años del mismo, se presenta una revitalización de los intermediarios político-económicos de extracción comunitaria y/o de círculos sociales primarios, a raíz del auge del tráfico de ganado argentino. A partir de los años cincuenta, al constituirse institucionalmente una mayor cercanía de personeros del Estado en las diversas comunidades rurales en general y atacameñas en particular, con un trabajo directo en el campo (Ediap, 1974), unido a un cambio cualitativo de las orientaciones ideológicas del profesorado rural en la zona, así como el surgimiento de intereses académicos y de ayuda solidaria por parte de la naciente Universidad del Norte (hoy, Universidad Católica del Norte). Es oportuno señalar la existencia de un espacio de intermediación, que se compone de por lo menos dos tipos genéricos de intermediarios, a los que hemos denominado intermediarios endógenos y exógenos:

Los intermediarios endógenos: son aquellos individuos surgidos de las comunidades atacameñas, pero que por circunstancias sociales y políticas concretas -coyunturas históricas específicas-, se separaron de la esfera de influencia directa de su comunidad de origen. Acercándose a la sociedad nacional obtuvieron conexiones de valor estructural, fundamentalmente en el mercado, tanto de bienes, servicios y en el mercado de trabajo. Situándose con el tiempo, ellos y sus familias, en una posición estratégica dentro de las relaciones de poder del nivel local, lo que les permitió especialmente en el ámbito económico, intermediar -conectar- el espacio local generador de insumos y con un creciente mercado comprador de la economía minera regional, especialmente el comercio del ganado argentino que circulaba por las comunidades de la cuenca del Salar de Atacama. Su influencia, por cierto, no se limitó al ámbito de lo económico, sino que abordó también lo político y lo social, pero siempre sustentándose en las relaciones de poder internas de las comunidades atacameñas.

Los intermediarios exógenos: Son en muchos aspectos opuestos a los intermediarios endógenos, aunque no necesariamente han sido antagónicos a lo largo de la historia reciente de las comunidades atacameñas. Desde lo estrictamente político, los funcionarios del Estado relacionados con la salvaguarda de fronteras -Carabineros-, Aduaneros, y personal del Servicio Agrícola y Ganadero-, sin duda han modificado los tradicionales intercambios transcordilleranos, pero con algunas excepciones limitadas no han constituido un espacio de intermediación entre lo local y lo regional-internacional. Un caso diferente, de intermediarios culturales por antonomasia han sido los profesores rurales, desde el primer momento de su arribo ya en tiempos coloniales (Hidalgo, 1982). Un caso similar lo han constituido los miembros de la Iglesia Católica y ahora, con particular fuerza, la presencia de diversas confesiones protestantes, quienes han impactado profundamente en los patrones culturales de las comunidades atacameñas. A mediados del presente siglo, a raíz de la consolidación de profundos cambios en la estructura y la orientación sistémica del Estado de Chile, la vinculación, y en muchos casos, el compromiso de algunos funcionarios, los aproximó a la dinámica interna de las comunidades ruralesindígenas, ocupando posiciones importantes en las mismas.

\section{La etnicidad y el mercado de trabajo en Atacama}

La notable presencia de la minería del cobre ha significado la continuidad del modo de producción extractivo-industrial. Lo que en un primer momento fue el salitre, ahora lo es el cobre. Esta continuidad ha tenido enormes repercusiones en la orientación de la economía de la región y del país, y como es de esperarse, también ha incidido radicalmente en la interconexión de los atacameños con la sociedad chilena, ya no sólo en aspectos económicos, sino en la más variada gama de tópicos.

En términos laborales, esta situación de continuidad ha conllevado la consolidación del asalariamiento como una instancia concretada interconexión étnica, que se manifiesta como un fenómeno claramente divergente de la situación acaecida con sus vecinos los aymaras. El mercado de trabajo no es el único punto de interrelaciones estructurales, esto es indiscutible, pero en este caso su importancia es protagónica en cualquier aproximación heurística a la realidad atacameña. Especialmente para el estudio de la etnicidad atacameña y sus consecuencias identitarias, desde la óptica de los efectos que esta inserción social y económica ha tenido la sociedad y la cultura 
vernácula

La minería del cobre ha sido bastante diferente a la del salitre. En esta última, uno de los motivos de la Guerra del Pacífico, el entorno social de la industria del salitre fue un marco clave en la consolidación del movimiento obrero, en la denominada «cuestión social» de Chile. Siguiendo a Pinto Vallejos (1994a y 1994b), así como a Pizarro (1986), se puede afirmar que los enclaves salitreros, generalmente de capitales británicos (Blakemore, 1977), absorvían mano de obra campesina criolla del sur del país, los cuales eran reclutados en sus comunidades de origen por «enganchadores» profesionales. A ellos se unían inmigrantes extranjeros y en una menor medida indígenas. La vida en las oficinas salitreras, era absolutamente vigilada por la gerencia de las mismas. $\mathrm{La}$ empresa controlaba la vivienda, los servicios (agua, combustible, etcétera), el abastecimiento alimenticio, entre otros. Pero la clave radicaba en que controlaba el valor de cambio monetario, al no pagar en dinero, sino que con «fichas» con equivalencia monetaria, las cuales sólo tenían valor en la oficina que las había emitido, por lo que los precios oscilaban y generalmente subían arbitrariamente, siguiendo las dictaminaciones de la empresa.

En síntesis, se formó en la industria del salitre una suerte de «cuello de botella» social, donde la inmensa mayoría de las aspiraciones y frustraciones se encauzaban en el medio laboral del campamento minero (Pinto Vallejos, 1994a). Como era esperable la situación social explotó, teniendo su trágico desenlace en la matanza de la escuela Santa María en la ciudad de Iquique, el 21 de diciembre de 1907. La minería industrial del cobre del siglo XX, por el contrario, si bien tuvo características similares, como la masiva presencia del capital extranjero (fundamentalmente de Estados Unidos), más población trabajadora migrante, tenía sin embargo diferencias fundamentales:

A) El valor bursátil del cobre a principios de siglo era menor que el del salitre, lo que se traducía en una menor rentabilidad (lo que cambiaría dramáticamente con el paso de los años), y con esto un estándar de vida de los trabajadores aún más paupérrimo que los del salitre (Latcham, 1926).

B) No se podía pagar en fichas, sino por el contrario se debía hacer en moneda nacional.

C) En 1924 (doce años después de la apertura del mineral de Chuquicamata) entró en vigor el Código del Trabajo, con una serie de leyes sociales que respondían en alguna medida a las demandas más sentidas de la cuestión social.

En dichos términos, la inserción laboral indígena, en este caso atacameña y boliviana, fue considerablemente diferente a la que tuvieron los aymaras de Tarapacá (y los atacameños durante el siglo XIX) en su momento. Esta ha sido de crucial importancia en la mencionada divergencia que han tenido estas dos etnias contiguas en su interrelación con la sociedad nacional chilena.

Las descripciones de la época, como la de Latcham (1926), así como las entrevistas testimoniales actuales, señalan que vivir en los diversos campamentos proletarios de Chuquicamata, significaba soportar condiciones de vida no sólo paupérrimas sino que además el ambiente en buena parte de los mismos, era de una gran inseguridad ciudadana; algunos de dichos campamentos eran reconocidos como antros de delincuencia, la ciudad vecina de Calama mostraba aspectos similares en las dificultades para vivir. Lo anterior en conjunto con salarios más bajos que los del salitre en su momento. Esto implicaba dificultades para los directivos estadounidenses en orden a encontrar mano de obra con espíritu de trabajo y sin mayores problemas sociales. Desde muy temprano entonces los indígenas atacameños y bolivianos tuvieron un lugar dentro de la faena productiva y no en la periferia, como fue el caso de los aymaras en las salitreras.

Con la quiebra del sistema económico a raíz de la crisis mundial de 1929, la industria del salitre colapsó, generando una enorme masa de obreros criollos sin trabajo, los cuales paulatinamente fueron ingresando a la minería del cobre a través de diversos mecanismos de absorción de cesantía puestos en acción durante la época, en gran medida por las leyes del Código del 'Trabajo de 1924. Siguiendo a Pinto Vallejos (1994a), en torno a la cuestión social en el norte chileno, podemos afirmar que los mineros salitreros, si bien no fueron los primeros en organizarse gremialmente (fueron los trabajadores portuarios), adquirieron a los pocos años, una gran capacidad de movilización y conocimiento político de las ideas anarquistas y marxistas, que les dieron una cobertura de confrontación laboral. Esta capacidad de ruptura fue justamente la que quería ser evitada, dentro de lo posible, por los directivos norteamericanos en Chuquicamata; en dichos términos, la continuación de la contratación de la mano de obra indígena (atacameños y bolivianos inmigrantes) puede ser entendida como la mantención de una población 
laboral alternativa a la criolla proveniente de las salitreras, que no poseía esa historia de luchas sindicales y cuya relación ya había demostrado ser generalmente buena con el estamento directo.

Una hipótesis central de este trabajo, es el postulado de una articulación socio-cultural múltiple de los atacameños en su relación con la sociedad nacional chilena. La base de esta articulación múltiple, ha sido el poseer la ligazón con sus comunidades de origen, a las cuales se puede volver temporalmente en momentos de recesiones económicas, aunque con las dificultades propias de comunidades pobres, las que no pueden sustentar abruptamente un ascenso poblacional. El trabajo asalariado, o las pensiones de jubilación, son el sustento económico de la mayoría de los casos estudiados, especialmente en los oasis piemontanos, siendo el trabajo familiar silvoagropecuario predial, el complemento minoritario de los ingresos de la unidad doméstica promedio (Rivera, 1994).

Para los directivos estadounidenses, hasta los años cincuenta, y de acuerdo con las primeras recopilaciones testimoniales, el mejor obrero era el que reunía las siguientes características: Provenir de un ambiente a-político partidista, sin mayores inquietudes sindicales, ojalá desarraigado socialmente, para tener un bajo perfil de necesidades, y adaptado al trabajo en esas condiciones medioambientales difíciles. Quienes mejor cumplían esos requisitos eran los migrantes bolivianos, aunque para mantener las buenas relaciones con el Estado chileno, la empresa nunca abrió totalmente la oferta laboral para ellos. Los atacameños de similares características fenotípicas que los anteriores, también cumplían varios de los requisitos, aunque ellos sí estaban profundamente y milenariamente arraigados en la zona, pero era y es un arraigo étnico-campesino, sin ideología revolucionaria ni sindicalismo conflictivo. Al último, la población criolla migrada hace décadas con redes sociales y políticas (partidos, sindicatos y lealtades patrias antiimperialistas).

Esta inserción diversificada de los atacameños ha sido relevante para ellos. Dado lo exiguo de su tamaño demográfico, no constituyeron un factor determinante en el rumbo que ha tenido la actividad económica de la región, incluida la minería industrial. Esta capacidad de transitar entre dos mundos culturales, en un principio, fue privilegio de contadas familias e individuos, especialmente durante la época del comercio del ganado argentino hacia las salitreras. Con el colapso de esa economía intermediaria, el potencial de esas redes familiares restringirlas, también decayó significativamente. Hoy en día, dada la profunda interdigitación entre las comunidades atacameñas y los centros urbano-industriales, el aparato estatal y el turismo en la zona, se puede considerar que las redes sociales, que son el soporte de esta interdigitación, son también en parte redes familiares, las que tienen una cobertura comunal de enorme importancia, más aún si consideramos que cumplen un importante rol ideológico, junto con otras interrelaciones estructurales. Por ejemplo, la re-etnificación desde el Estado, en ocasiones llamada también la recuperación ele la identidad étnica de los pueblos originarios, como objetivo de la Ley Indígena de 1993. Las consecuencias de este cuerpo legal, en la actual configuración de la etnicidad atacameña contemporánea, no pueden sino considerarse como fundamentales.

Por otra parte, la distinción social y cultural que hace a los atacameños étnicamente diferentes de los demás miembros de la sociedad chilena, se ha dado también en esta interrelación estructural. Postulamos que la «dicotomización», es decir, la percepción identitaria de la mencionada distinción (nosotros/ellos), se ha conformado más en los lugares de encuentro como el mercado de trabajo, y la contigüidad habitacional en las ciudades y campamentos mineros, que en el mantenimiento del «refugio étnico» del terruño ancestral. Los puntos de encuentro son muchos y muy variados, pero consideramos pertinente rescatar la importancia de las relaciones laborales y el acceso a las mismas, ya no sólo por dicotomización, sino también por la «complementación» (la articulación social de la alteridad) de las diferencias étnico-culturales. Entendido así, nos retrotraemos a Barth (1976), y otros, quienes han abordado las fronteras étnicas como un fenómeno complementario, en donde la identidad étnica se construye también por oposición y diferenciación frente a los otros. El punto diferente de los atacameños, que ha causado confusión en los diagnósticos socioculturales sobre ellos, es a nuestro entender que ambos procesos, la dicolomización y la complementación étnica se han realizado inusitadamente próximos a los centros económicos y de poder de la modernidad nacional, como la minería industrial.

\section{Conclusiones}

La emigración de la población atacameña desde las comunidades campesinas hacia contextos urbanos $\mathrm{u}$ otros propios de la modernidad es un fenómeno constatado por investigadores de las más variadas tendencias teóricas. Sin embargo, prevalece la no- 
ción de la destrucción aculturadora de este contacto visto como subordinación social y política. Incluso en trabajos del área de educación (Collao y Sepúlveda, 1992), se plantea que aun siendo la educación formal uno de los agentes que históricamente más han contribuido a la aculturación indígena en la zona, ésta puede revertir su papel histórico, para rescatar lo que aún queda de la cultura vernácula, sugiriendo integrarla a macro proyectos de desarrollo regional, todo lo cual debería ser financiado por las empresas mineras que trabajan en la zona. Algo similar fue planteado hace treinta años aproximadamente, por la OPRIL (Organización de Profesores Rurales del Interior del Loa) (Gómez, 1994) y el «Plan Cordillera» de la Iglesia Católica-Universidad del Norte durante la década de 1960 hasta alrededor de 1971.

En ese mismo año de 1971, dejó de funcionar también la Cooperativa Agrícola de San Pedro de Atacama (fundada en 1957), disminuyó ostensiblemente la presencia de la CORFO, en resumen, dada la explosión de demandas sociales encauzadas por el gobierno de Allende, los recursos gubernamentales se enfocaron hacia otras realidades del país que exigían un apoyo inmediato. Con el gobierno militar de Pinochet desde 1973, se consolidó esta retirada del Estado de la región atacameña, en algunos rubros importantes. A partir del proceso de creación de municipalidades en 1980, nacen los municipios de San Pedro de Atacama y Ollagüe, iniciándose una renovada intervención del Estado bajo el gobierno militar, la cual unida a la presencia de organismos privados, ONGs u otras, constituyeron las pautas estructurales de interrelación sociedad criolla/ atacameños en la zona hasta la asunción de la democracia en 1990 y la promulgación de la ley indígena en 1993.

El entorno criollo nacional ha cambiado en algunos aspectos profundamente, ya sea que consideremos los últimos treinta años, todo este siglo, o más atrás. El cuestionamiento que surge entonces es: ¿Qué clase de cambios han tenido los atacameños en este mismo tiempo, cambios desintegradores de su

3 Se refiere a que la construcción étnica de la filiación racial se centra en el componente minoritario del parentesco, por ejemplo: si de los 16 tatarabuelos de una persona, quince fueron blancos y uno indígena, el tataranieto es considerado legalmente indígena. identidad étnica, o cambios reformuladores de esa misma identidad? Pensamos que ha ocurrido esto último, y no por azar, asi como tampoco por fría racionalidad estratégica, sino simplemente por la razón más básica y hasta ahora casi no tomada en cuenta, es decir: la cotidianidad de la vida diaria amerita una constante adaptación a múltiples desafíos, la capacidad de vivir lo cotidiano sin morir en el intento, manteniendo o modificando algunos niveles de la identidad y la voluntad expresada en pequeñas y grandes decisiones, que son la expresión de la «agencia humana», la capacidad de las personas de participar activamente de los procesos sociales que los involucran.

Esto se complementa con los cambios y las pervivencias estructurales que han marcado los procesos sociales en Atacana en particular y en la región andina en general. La misma comunidad andina $y / o$ atacameña que conocemos hoy, valorada como el reducto de la pureza étnica por antonomasia, es ya producto de la hibridación cultural colonial, del ayllu precolombino y la comunidad española de los siglos XVI y XVII (Fuenzalida, 1976). Por otra parte, la normatividad racial de la colonia no era de hipofiliación como en los países sajones (Alemania, Holanda, Sudáfrica, USA, etc.) $)^{3}$. Este término acuñado por Marvin Harris y Conrad Kottak en 1963 (citados en Kottak, 1994: 81), digamos que la hipofiliación es el racismo de la paranoia angustiante, lo que no se aplicó en la América española y portuguesa durante la colonia ni en las repúblicas posteriores, lo que no niega la existencia de la segregación étnico-racial por otras vías, como se ha constatado en múltiples ocasiones. Por lo menos, en términos meramente legales, existe una voluntad asimilacionista, que en Atacama durante el período republicano chileno llegó al extremo de negar la existencia oficial de la etnia Likán Antai, por lo que la defensa de sus derechos no podía realizarse en un escenario de revindicaciones étnicas. Las consecuencias de esto son variadas, desde la búsqueda de la ciudadanía a través de la conquista de espacios criollos como el mercado de trabajo asalariado, la visión positiva de la educación formal, la inscripción de apellidos castellanos, entre otros; pero también trajo consigo fuertes segregaciones intracomunitarias e intercomu-nitarias de los más criollizados hacia los llamados «coyas», sobre todo en el manejo de recursos con trascendencia económica.

La circulación poblacional o migraciones es antiquísima en Atacama, la cual además de los aspectos económicos y demográficos, tiene una importancia 
fundamental en el acceso de los conocimientos cotidianos e imprescindibles del ser un ciudadano competente; es decir, capacitarse en el habitus bourdiano, que permita ya no sólo tener una ciudadanía formal sino también real, con todo el riesgo aculturativo que esto implica. Este aspecto fundamental, fue algo que no tomaron en cuenta la mayoría de los proyectos de apoyo a las comunidades atacameñas en la región, hasta que finalmente fueron sobrepasados por los hechos protagonizados por los propios agentes atacameños, su voluntad de ser competentes en la modernidad, y no, necesariamente, sólo por el peso institucional de la sociedad chilena en su espacio étnico, expresada en el servicio militar, las municipalidades, las escuelas secundarias en Calama, o el mercado de trabajo minero, entre otros.

Esta búsqueda de la ciudadanía real es un elemento fundamental para entender la transición propiciada por la reciente ley indígena de 1993, de una etnicidad atacameña que se desenvolvía en la esfera privada, como la sexualidad, ritos domésticos y patrones de consumo cultural, a una etnicidad en la esfera pública, que construye discursos étnicos para las demandas de financiamiento gubernamental, y/o resguardos privilegiados de los recursos vernáculos, etcétera. En síntesis, la emigración ha sido mucho más que válvula de escape de la pobreza y de la presión de población sobre los escasos recursos de los oasis atacauneños. Ha sido una estrategia, exitosa o deficiente (esto sólo se puede saber a posteriori) para adquirir los conocimientos vivenciales cotidianos, a fin de asegurar el sustento económico y la competencia indispensable para ejercer una ciudadanía efectiva y trascendente en el tiempo.

\section{BIBLIOGRAFIA}

ARANDA, Ximeua; Rafael BARAHONA y René SAA. Elemen1968 tos diagnósticos para un plan de desarrollo local en San Pedro de Atacama. Santiago de Chile. Informe paca la Corporación de Fomento de la Producción (CORFO), Departamento de Desarrollo Agrícola. [1964].

AYLWIN AZOCAR. Patricio. Mensaje de S.E. el Presidente 1991

$$
\text { de la República, con el que se inicia un }
$$
proyecto de Ley relativo a la protección, fomento y desarrollo de los pueblos indígenas. (Mensaje $\mathrm{N}^{0}$ 05-323) a S. E. el Presidente de la Honorable Cámara de Diputados y miembros de la misma. Santiago de Chile. República de Chile. Ministerio Secretaría General de la Presidencia. I1990].

BA12'l'Ii, Fredrik. «Introducción». En Los grupos étnicos y sus 1976 fronteras. la organización social de las diferencias culturales (Fredrik Barth, Ed.). México D.F., Fondo de Cultura Económica.

BENGOA CABELLO, José. «Breve historia de la legislación in1991 dígena de Chile» En Etnia y Nación en América Indígena (Héctor Díaz-Polanco, comp.). México D.F. Consejo Nacional para la Cultura y las Artes (CNCA).

BLAKEMORE, Harold. Gobierno chileno y salitre inglés 18861977 1896: Balmaceda y North. Santiago de Chile. Editorial Andrés Bello (Sofía Varela. trad.).
BONILLA, Heraclio. EI minero de los Andes. Una aproxima1974 ción a su estudio. Lima, instituto de Estudios Peruanos.

CAJIAS DE LA VEGA, Fernando. La provincia de Atacama 1975 (1825-1842). La Paz. Universidad Mayor de San Andrés/Instituto Boliviano de Cul tura. Empresa Editora Universo.

CAÑETE Y DOMINGUEZ, Pedro Vicente. Guía histórica, geo1952 grálica, política, civil y legal del Gobierno e intendencia de Potosí. La Paz. Editorial Potosí. [1767].

CASSASAS CANTO, José María. La región atacameña en el 1974 siglo XVII. Santiago de Chile. Editorial Universitaria.

CLUB DE LOS CHULULOS. El Chululo año 1, $\mathrm{N}^{\circ} 1$. (Órgano 1957 oficial del «Club de los Chululos»). San Pedro de Atacama.

COLLAO, Sigfrido y Robert SEPÚLVEDA. Situación educa1992 cional y migracional de la población emigrante a la ciudad de Calama, de cuatro pueblos atacameños del río Loa superior. Tesis para optar al grado de Licenciado en Ciencias de la Educación. Antofagasta. Universidad de Antofagasta.

CONSECOL (Consultores ecológicos y ambientales limitada). 1988 Diagnóstico agrícola de la Provincia El Loa (4 vols.). Antofagasta. Secretaría Regional de Planificación y Coordinación (SERPLAC). II Región. República de Chile. 
CONTRERAS. Carlos. Mineros Campesinos en los Andes. 1988 Mercado laboral y economía campesina en la Sierra Central, siglo XIX. Lima. Instituto de Estudios Peruanos.

DE VOS, George and Lola ROMANUCCI-ROSS. «Ethnicity:

1982 Vessel of meaning and emblem of contrast». En Ethnic Identity. Cultural continuities and change. (George De Vos and Lola RomanucciRoss, eds.). Chicago. University of Chicago Press.

DE WIND, Adrián. «De campesinos a mineras: El trasfondo de 1985 las huelgas en las minas del Perú». En Allpanchis Phuturinqa N²6. Cusco.

DEVES, Eduardo. Los que van a morir te saludan. Historia de 1997 una masacre: Escuela Santa María de Iquique, 1907. Santiago. LOM Ediciones.

EDIAP BERRIOS, Luis. Seis años de labor en el desarrollo agrí1974 cola de San Pedro de Atacama Antofagasta. (m.s.)

FUENZALIDA, Fernando. «La estructura de la comunidad indí1976 gena tradicional». En Hacienda, comunidad y campesinado en el Perú. (José Matos Mar, comp.). Lima. Instituto de Estudios Peruanos.

GOBEL, Barbara y Fanny DELGADO. «Susques durante la Go1993 bernación de los Andes: Un caso paradigtnático para el análisis (le la relación EstadoPeriferia» (Ponencia) En Primer Seminario de Integración Subrregional. Iquique.

GODOY. Ricardo. «Mining: Anthropological perspectives». En 1985 Annual Review of Anthropology vol.14. Palo Alto. Annual Reviews Inc.

GOMEZ Parra, Domingo. Propuesta para una política educa1994 cional para el minio y el joven atacameño de 5 a 18 arcas de edad. Tesis para optar al grado de Magister en Administración Educacional. Antofagasta. Universidad de Antofagasta.

HECHTER, Michael. Internal colonialism. The celtic fringe in 1975 british national development. London. Routledge and Kegan Paul.

HIDALGO LEDEHUE, Jorge. « Descomposición cultural en Ata1982 cama en el siglo XVIII: Lenguas, escuela, fugas y complementariedad». En Simposio: Culturas Atacameñas. San Pedro ele Atacama. Universidad del Norte.

1985 «Ecological complementarity and tribute in Atacama: 1632-1792». En Andean ecology and civilization (Shozo Mazuda, Izumi Shimada and Craig Morris. comps.) Tokio. University of Tokio Press.

1987a «Chiefdoms of the andean southwest: Origin and colonial evolution». En Chiefdoms in Americas (Robert Drennan and Carlos Uribe, comps.). Lanham. University Press of America.

1987b «Tierras, exacciones fiscales y mercado en en las sociedades andinas de Arica. Tarapacá y Atacama: 1750-1790». En La participación indígena en los mercados surandinos (Olivia Harris, Brooke Larson y Enrique Tandeter, comps.). La Paz. CERES.
JARA, Alvaro. Trabajo y salario indígena, siglo XVI. San-

1987 tiago. Editorial Universitaria.

KOTIAK, Conrad Philip. Antropología. Una exploración de la diversidad humana. Madrid. McGrawHill/Interamericana de España.

LATCHAM, Ricardo A. (1926). Chuquicamata: Estado Yankee (Visión de la montaña roja). Santiago de Chile. Editorial Nascimento.

MALENGREAU, Jacques. «Comuneros y empresarios en el in1974 tercantbio». En Reciprocidad e intercambio en los Andes peruanos (Giorgio Alberti y Enrique Mayer, comp.). Lima. Instituto de Estudios Penamos.

1992 Espacios Institucionales en los Andes. Lima. Instituto de Estudios Peruanos/Uni-versidad Libre de Bruselas.

MAYER, Enrique. «Las reglas del juego en la reciprocidad andi1974 na». En Reciprocidad e intercambio en los Andes peruanos (Giorgio Alberti y Enrique Mayer, comp.). Lima. Instituto de Estudios Peruanos.

MOSTNY, Grete; Fidel JELDES, Raúl GONZALEZ y Francis1954 co OBERHAUSER. Peine. Un pueblo atacameño. Santiago de Chile. Universidad de Chile.

MURRA, John V. Formaciones económicas y políticas del

1975 mundo andino. Lima. Instituto de Estudios Peruanos.

1989 La organización económica del estado Inca. México D.F. Siglo XXI Editores (Daniel Wagner, trad.). [1955]

NASH, June. We eat the mines and the mines eat us. Dependency

1993 autpl. and explotation in bolivian tin mines New York. Columbia University Press

NUÑEZ Atencio, Lautaro. Cultura y conflicto en los oasis de 1992 San Pedro de Atacama. Santiago. Editorial Universitaria

NUÑEZ, Lautaro y Toni DILL,L I IAY. Movilidad giratoria, ar1995 monía social y desarrollo en los Andes. Patrones de tráfico e interacción económica. Antofagasta. Universidad Católica del Norte.

PINTO VALLEJOS, Julio. «La Transición laboral en el norte sali1994a trero: La provincia de Tarapacá y los orígenes de la cuestión social, 1870-1890». En Trabajadores mineros: Vida y Cultura. México D.F. Ltstituto Nacional ele Antropología e Historia.

1994b «Minería e industrialización: La economía del norte chileno y los inicios de la industria nacional, 1850-1914». En Minería americana colonial y del siglo XIX. México D.F. lust ituto Nacional de Antropología e Historia.

PIZARRO, Crisóstomo. La huelga obrera en Chile 1890-1970. 1986 Santiago de Chile. Ediciones SUR

RIVERA FLORES, Francisco. «La marginalidad, vínculo entre 1993 la etnicidad y la globalidad: El caso de San Pedro de Atacama. Chile». En Contextos étnicos del lenguaje. Aportes en Educación y Etnodiversidad. (Héctor Muñoz y Rossana Podestá, eds.). Oaxaca. Universidad Autónoma ‘Benito Juárez' de Oaxaca. 
La apropiación social de recursos en San Pedro de Atacama, Chile (ms)

1994

1995 Universidad Católica del Norte.
«Identidad en el laberinto: La búsqueda del sentido étnico en San Pedro de Atacama» En Estudios Atacameños $N^{\circ} 11$. San Pedro de Atacama.

«Contexto histórico y social del manejo de los recursos agropecuarios en los oasis de San Pedro de Atacama» En Agua, ocupación del espacio y economía campesina en la región atacameña. Aspectos dinámicos. (Pierre Pourrut y Lautaro Núñez, eds). Antofagasta. Institut Français de Recherche scientifique pour le développement en Coopération (ORSTOM)/Universidad Católica del Norte.

RIVERA FLORES, Francisco y Pierre POURRUT «La falta de 1994 agua en el norte de Chile. De problema étnico a crisis nacional» (Ponencia) En ILVIII International Congress of Americanists. Stockholm.

ROOSENS, Eugeen E. Creating Ethnicity. The process of 1989 ethnogenesis. Newbury Park. Sage Publications.

SALAZAR VERGARA, Gabriel. Labradores, Peones y Proleta1989 ríos. Formación y crisis de la sociedad popular chilena del siglo XIX. Santiago de Chile, Ediciones SUR. [1985].

SANHUEZA, María Cecilia. «Tráfico caravanero y arriería colo1992 nial en el siglo XVI». Estudios Atacameños $N^{\circ} 10$. San Pedro de Atacama. Universidad Católica del Norte.

SMITH, Anthony. The ethnic origins of nations. Oxford. Blackwell. 1993

SPALDING, Karen. De Indio a Campesino: Cambios en la es1974 tructura social del Perú colonial. Lima Instituto de Estudios Peruanos.
STAVENHAGEN, Rodolfo. «La cuestión étnica. Algunos pro1992 blemas teórico-metodológicos». En Estudios Sociológicos vol X, N²8. México D.F. El Colegio de México.

TAGUIEFF, Pierre-André. La force du préjugé. Essai sur le 1987 racisme et ses doubles. Paris. Éditions La Découverte.

TAUSSIG, Michael. El diablo y el fetichismo de la mercancía 1993 en Sudamérica. México D.F. Editorial Nueva Imagen (Juan Utrilla, trad.).

URBAN, Greg and Joel SHERZER. «Introduction: Indians. 1991 Nation-States, and culture». En NationStates and indians in Latin America (Greg Urban and Joel Sherzer, eds.). Austin. The University of Texas Press.

VAN KESSEL BROUWERS, Johannes. Holocausto al Progre-

1980 so. Los Aymaras de Tarapacá. Amsterdam. CEDLA/Vrije Universiteit.

1991 Los Aymaras bajo el régimen militar de Pinochet. Iquique. CREAR.

VILLAR, Daniel. The politics of decentralization in Chile: 1992 Allende and Pinochet. (Degree's Dissertation of Master of Arts). Washington D.C. The American University/Ann Arbor. UMI Dissertation Services.

YINGER, J. Milton. Ethnicity: Source of strength?, source of 1994 conflict?. Albany. State University of New York Press.

ZAPATA Schaffeld, Francisco. «La acción sindical en la gran 1986 minería del cobre: ¿Continuidad o ruptura?». En Clases sociales y acción obrera en Chile. (Francisco Zapata, comp.) México D.E. El Colegio de Mexico.

1992 Atacama. Desierto de la discordia. México D.F. El Colegio de México. 
